\title{
REINVENT: ERS International survey on REstrictive thoracic diseases IN long term home noninvasive VENTilation
}

\author{
Paola Pierucci (10 ${ }^{1,2}$, Claudia Crimi (103 ${ }^{3}$, Annalisa Carlucci ${ }^{4,5}$, \\ Giovanna E. Carpagnano ${ }^{1,2}$, Jean-Paul Janssens ${ }^{6}$, Manel Lujan ${ }^{7}$, \\ Alberto Noto ${ }^{8,9}$, Peter J. Wijkstra ${ }^{10,11}$, Wolfram Windisch ${ }^{12}$ and Raffaele Scala ${ }^{13}$
}

\section{ABSTRACT}

Background and aim: Little is known about the current use of long-term home noninvasive ventilation (LTHNIV) in restrictive thoracic diseases, including chest wall disorders and neuromuscular disorders (NMD). This study aimed to capture the pattern of LTHNIV in patients with restrictive thoracic diseases via a web-based international survey.

Methods: The survey involved European Respiratory Society (ERS) Assembly 2.02 (NIV-dedicated group), from October to December 2019.

Results: 166 (22.2\%) out of 748 members from 41 countries responded; 80\% were physicians, of whom $43 \%$ worked in a respiratory intermediate intensive care unit. The ratio of NMD to chest wall disorders was 5:1, with amyotrophic lateral sclerosis the most frequent indication within NMD (78\%). The main reason to initiate LTHNIV was diurnal hypercapnia (71\%). Quality of life/sleep was the most important goal to achieve. In $25 \%$ of cases, clinicians based their choice of the ventilator on patients' feedback. Among NIV modes, spontaneous-timed pressure support ventilation (ST-PSV) was the most frequently prescribed for day- and night-time. Mouthpieces were the preferred daytime NIV interface, whereas oronasal masks the first choice overnight. Heated humidification was frequently added to LTHNIV (72\%). Single-limb circuits with intentional leaks (79\%) were the most frequently prescribed. Follow-up was most often provided in an outpatient setting.

Conclusions: This ERS survey illustrates physicians' practices of LTHNIV in patients with restrictive thoracic diseases. NMD and, specifically, amyotrophic lateral sclerosis were the main indications for LTHNIV. NIV was started mostly because of diurnal hypoventilation with a primary goal of patientcentred benefits. Bi-level ST-PSV and oro-nasal masks were more likely to be chosen for providing NIV. LTHNIV efficacy was assessed mainly in an outpatient setting.

@ERSpublications

For the first time since EUROVENT, the REINVENT survey of @EuroRespSoc members expert in noninvasive (NIV) ventilatory support illustrates physicians' practices of long-term home NIV in restrictive thoracic disorder patients https://bit.ly/2MbC3YI

Cite this article as: Pierucci $\mathrm{P}$, Crimi $\mathrm{C}$, Carlucci A, et al. REINVENT: ERS International survey on REstrictive thoracic diseases IN long term home noninvasive VENTilation. ERJ Open Res 2021; 7: 00911-2020 [https://doi.org/10.1183/23120541.00911-2020].

This article has supplementary material available from openres.ersjournals.com.

Received: 4 Dec 2020 | Accepted: 21 Jan 2021

Copyright $\odot$ The authors 2021. This version is distributed under the terms of the Creative Commons Attribution NonCommercial Licence 4.0. For commercial reproduction rights and permissions contact permissions@ersnet.org 


\section{Introduction}

In the mid-1980s, noninvasive ventilation (NIV) became the reference treatment for chronic respiratory failure. This allowed a drastic decrease in invasive ventilation (tracheostomy), while improving survival, quality of sleep and quality of life in patients with both obstructive and restrictive thoracic disorders (RTD) [1-4]. Over recent decades, the management of home NIV has changed dramatically [5-7].

Published data support the use of NIV in RTD patients and have shown its clinical and physiological benefits. Long-term NIV increases the likelihood of prolonged survival and thus most often allows the avoidance of tracheostomy and home invasive mechanical ventilation. Except for a few randomised controlled trials in amyotrophic lateral sclerosis (ALS) [8], the positive impact of NIV in RTD is based mainly on observational uncontrolled studies. Survey-based findings represent a valuable alternative source of data. They can reliably describe the practices of clinicians in different domains of medicine, such as home noninvasive ventilation.

In 2005, the EUROVENT survey provided a comprehensive picture of practices regarding home mechanical ventilation (HMV) in patients with chronic respiratory failure across 16 European countries [9]. For the first time, it identified patterns of use and settings of HMV across Europe. For the first time, it identified patterns of use and settings of HMV across Europe, helping many physicians in their clinical practice, through the information gathered.

Since the EUROVENT survey, there has been no follow-up study of the use of NIV in patients affected by RTD across Europe. Indeed, there is an evident gap in the literature on this topic. Updating information on settings, interfaces and modalities of NIV use in Europe (i.e. mouthpiece ventilation) is necessary and warranted [10-14]. To the best of our knowledge, only a few studies in the literature have tried to assess settings and current NIV practices in RTD [7, 15-19].

Therefore, we performed an international survey to collect NIV users' experience and report current clinical real-world practices for REstrictive disorders IN long term home noninvasive VENTilation: REINVENT.

\section{Material and methods}

\section{Survey development}

This web-based survey was developed using SurveyMonkey, an online platform with a cloud-based survey development application.

The ideated survey was then conducted to explore physicians' clinical management of long-term NIV in the treatment of chronic respiratory failure due to RTD. For the purpose of the survey, long-term home noninvasive ventilation (LTHNIV) included only patients with RTD as defined hereafter. Respiratory diseases included were chest-wall deformity, neuromuscular diseases (NMD), spinal cord injury, phrenic nerve paralysis, fibrothorax post-tuberculosis, and thoracoplasty. We excluded patients with obesity hypoventilation syndrome or parenchymal restrictive lung diseases. A list of illnesses included was provided on the first page of the survey with a brief explanation of the aim of our research.

The survey was developed based on previous work, exploring physicians' perceptions as to use of NIV [20-22]. The survey instrument was designed after a thorough literature review to generate relevant survey items. A panel of European Respiratory Society (ERS) experts on NIV, part of the steering committee of the project, reviewed the survey items for content validity, relevance and ability to discriminate among

Affiliations: ${ }^{1}$ Cardiothoracic Dept, Respiratory and Critical Care Unit Bari Policlinic University Hospital, Bari, Italy. "2"Aldo Moro" Bari University School of Medicine, Bari, Italy. ${ }^{3}$ Respiratory Medicine Unit, "PoliclinicoVittorio Emanuele San Marco" University Hospital, Catania, Italy. "Reparto Pneumologia Riabilitativa Istituti Clinici Scientifici Maugeri Pavia, Pavia, Italy. ${ }^{5}$ Dipartimento di Medicina e Chirurgia, Università Insubria Varese-Como, Varese, Italy. 'Division of Pulmonary Diseases, Geneva University Hospitals, Geneva, Switzerland. ${ }^{7}$ Pneumology Service, Hospital Universitari Parc Taulí de Sabadell, Universitat Autònoma de Barcelona, CIBERES, Sabadell, Spain. ${ }^{8}$ Dept of Human Pathology of the Adult and Evolutive Age "Gaetano Barresi", Division of Anesthesia and Intensive Care, University of Messina, Policlinico "G. Martino", Messina, Italy. ${ }^{9}$ IPCF-CNR, Institute for Chemical and Physical Processes, National Research Council, Messina, Italy. ${ }^{10}$ Dept of Pulmonary Diseases/Home Mechanical Ventilation, University of Groningen, University Medical Center Groningen, Groningen, the Netherlands. ${ }^{11}$ Groningen Research Institute for Asthma and COPD (GRIAC), University of Groningen, University Medical Center Groningen, Groningen, the Netherlands. ${ }^{12}$ Cologne Merheim Hospital, Dept of Pneumology, Kliniken der Stadt Köln; gGmbH Witten/Herdecke University, Faculty of Health/School of Medicine, Cologne, Germany. ${ }^{13}$ Pulmonology and Respiratory Intensive Care Unit, S Donato Hospital, Arezzo, Italy.

Correspondence: Paola Pierucci, Policlinico di Bari, Ospedale Giovanni XXIII, Piazza Giulio Cesare 12, 70124 Bari, Italy. E-mail: paola.pierucciapoliclinico.ba.it 
respondents. The ERS management group then revised the survey by adding further details based on previous proposed survey studies. The final survey questionnaire included various formats such as Likert scales, ranking and yes/no, but did not allow for open-ended questions.

The survey consisted of three parts. The first part included general questions about the participants' professional status, general characteristics, experience with LTHNIV in the treatment of RTD and the type of RTD most often encountered in their hospital practice. The second part was mainly centred on reasons for NIV initiation, clinical benefits expected and characteristics of ventilators used: pre-set modes, circuits, interfaces and humidification. Ventilation pre-set modes were defined as follows: mouthpiece ventilation (MPV), spontaneous pressure support ventilation (S-PSV), spontaneous-timed PSV (ST-PSV), PSV with target volume (TV-PSV), pressure-controlled ventilation (PCV), continuous positive airway pressure (CPAP) and volume-controlled ventilation (VCV). The third and last part was referred to as "timing and type of follow-up". The full survey is presented in the supplementary material.

\section{Survey testing}

We administered the survey to 10 respondents, including pulmonologists and critical care physicians, to test comprehensiveness, clarity and validity. We estimated inter-rater reliability using Cohen's $\kappa$-test with a threshold value $>0.4$ (i.e. moderate agreement).

\section{Survey administration}

To identify clinicians interested and involved in NIV practices, we contacted the members of ERS assembly 2, group 2.02. This group is a heterogeneous, multidisciplinary and multiprofessional group, incorporating physicians with different educational backgrounds, such as pulmonology, anaesthesiology, internal medicine, intensive care medicine and emergency medicine, as well as allied healthcare professions (nurses and physiotherapists). These professional figures participate together in this group based on their common interests and expertise in NIV practice.

Email notifications with a link to a web-based questionnaire were sent in September 2019 to all 748 members of ERS assembly 2, group 2.02. Reminders were sent every 4 weeks. The survey was closed in December 2019.

\section{Data entry and analysis}

We reported descriptive statistics, including proportions, means \pm SD or median (interquartile range (IQR)), when appropriate.

The respondents were grouped based on the type of ward in which they principally worked: 1) critical care (emergency department, intensive care unit (ICU), pulmonary ward + high-dependency unit); and 2) general (pulmonary ward and general ward versus rehab, private practice, outpatient clinic) to allow comparisons. Contingency tables were computed, and proportions were compared using the Chi-squared test. Analyses were performed using SPSS version 24 (IBM, Armonk, NY, USA). A p-value $<0.05$ was considered significant.

\section{Results}

\section{Survey response rate}

Out of the 748 ERS assembly 2.02 members, 166 healthcare professionals responded to the survey, i.e. a response rate of $22.1 \%$. Respondents belonged to 41 different countries: 19 European and 22 non-European countries. The full list is included in the supplementary material.

\section{Respondents' characteristics}

The majority of responders worked in university teaching hospitals (64.8\%), followed by community hospitals (22.4\%), rehabilitation centres (6.7\%), private hospitals/clinics (4.2\%) and outpatient clinics (1.8\%). They worked mainly in respiratory wards with a dedicated respiratory intermediate ICU (43\%). Distribution of other facilities is shown in table 1. Responders belonged to different healthcare professions: physicians, physiotherapists, nurses and others. The most represented were physicians (80\%). They were generally very experienced in NIV, most of them having >10 years of experience (61\%). $15 \%$ of respondents reported $>50$ ventilator prescriptions per year.

\section{Indication for LTHNIV}

NMD was the most important indication for $80.9 \%$ of the respondents, with ALS representing $78 \%$ of these cases, followed by Duchenne muscular dystrophy (11\%), chest-wall deformity (14.5\%) and others (4.6\%).

The most important reasons for initiating LTHNIV reported by respondents are shown in figure 1 . Respondents ranked the most significant treatment targets to achieve using LTHNIV, as shown in figure 2. 


\section{TABLE 1 Institutions' characteristics}

Pulmonary ward + respiratory ICU

Pulmonary ward

Pulmonary rehabilitation and/or chronic ventilator facilities

\section{Others}

Pulmonary outpatient clinic/consultation

Data are presented as $\mathrm{n}(\%)$. ICU: intensive care unit.

\section{Instruments and settings}

Participants were more likely to choose a specific ventilator based on the following characteristics of devices: good feedback from patients (25\%), presence of both pressure and volume ventilation options and transportability (20\%) (figure 3).

The majority of interviewees used MPV during daytime only (65\%), followed by S-PSV (17\%) and ST-PSV (9\%). MPV was more frequently used in general respiratory wards (rehabilitation and acute wards) than in critical care wards (ICU, respiratory ICU, emergency department) $(p=0.015)$. Respondents reported that TV-PSV (29\%) was the preferred mode of ventilation during night-time, followed by PCV (20\%), ST-PSV (19\%), CPAP (18\%) and VCV (10\%). However, if one mode was chosen for both day- and night-time ventilation, then ST-PSV was the most frequently used (36\%), followed by TV-PSV (25\%), PCV (16\%) and VCV (15\%). All modalities used between daytime and night-time are detailed in figure 4.

Clinicians were more likely to use single-limb circuits with intentional leaks or exhalation ports (79\%), followed by expiration valves (13\%) and double-limb circuits (8\%).

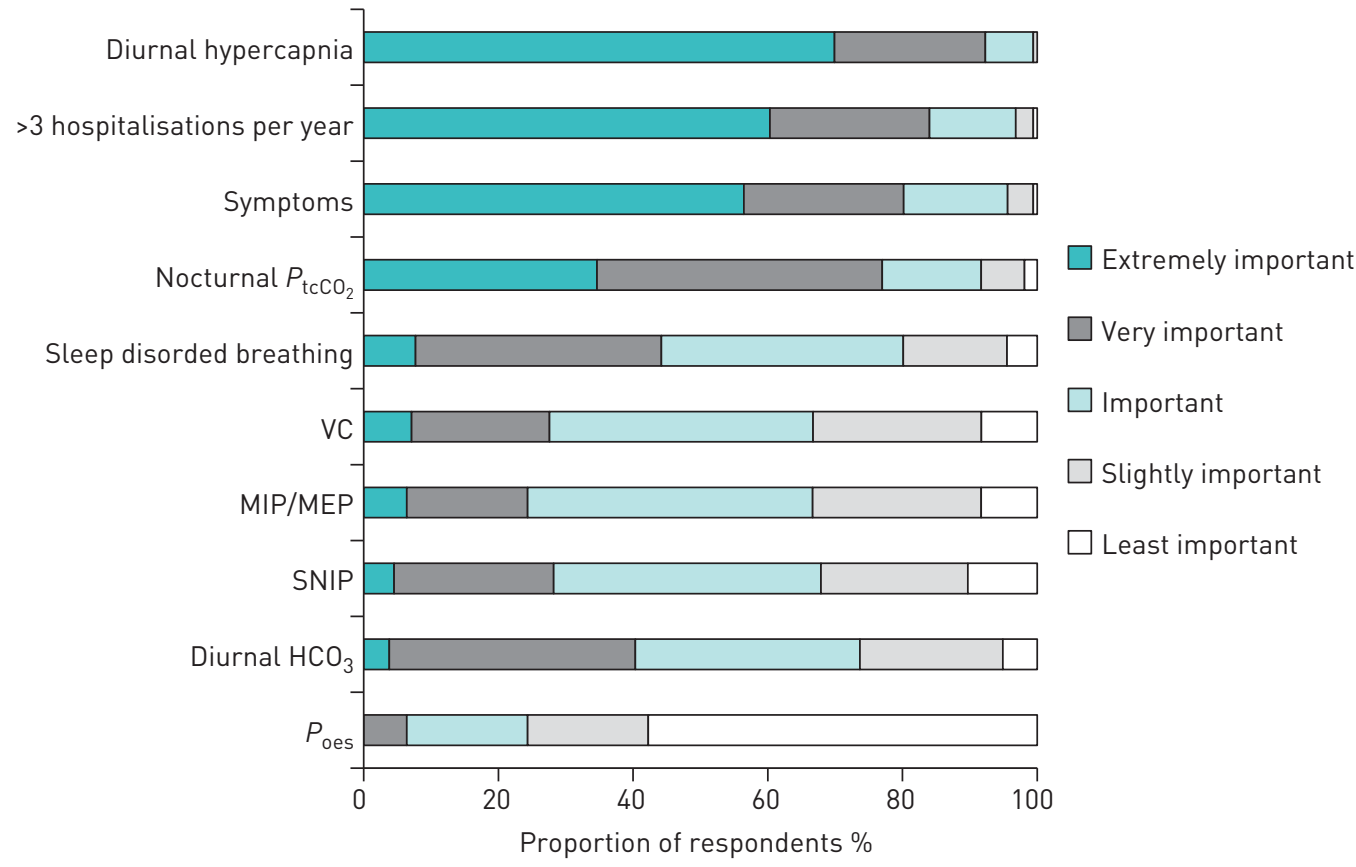

FIGURE 1 Reasons to start long-term home noninvasive ventilation in restrictive thoracic disorders. $P_{\mathrm{tcC02}}$ transcutaneous carbon dioxide tension; VC: vital capacity; MIP: maximal inspiratory pressure; MEP: maximal expiratory pressure; SNIP: sniff nasal inspiratory pressure; $\mathrm{HCO}_{3}$ : bicarbonate; $P_{\text {oes}}$ : oesophageal pressure. 


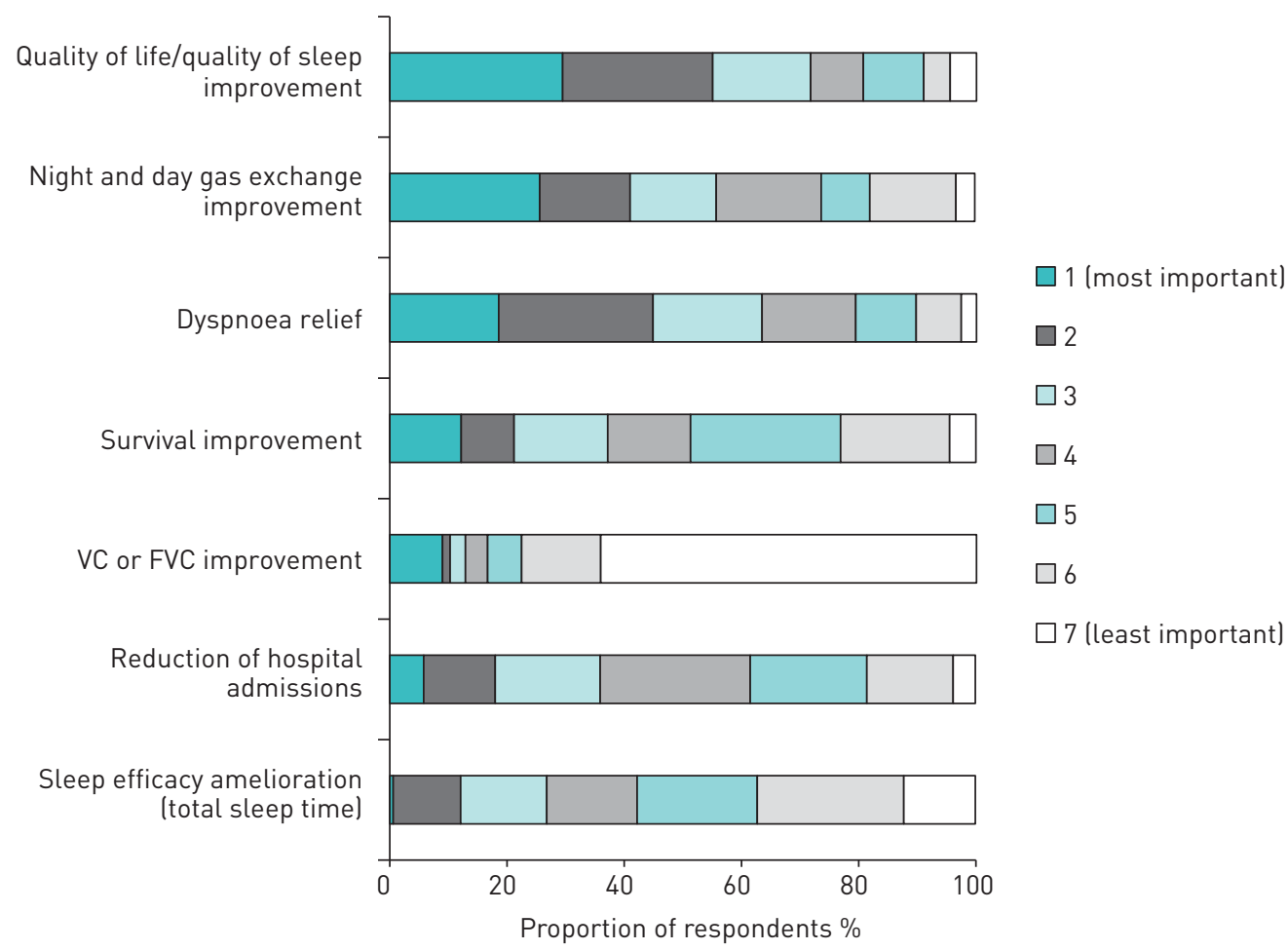

FIGURE 2 Treatment targets of long-term home noninvasive ventilation for restrictive thoracic disorders. VC: vital capacity; FVC: forced vital capacity.

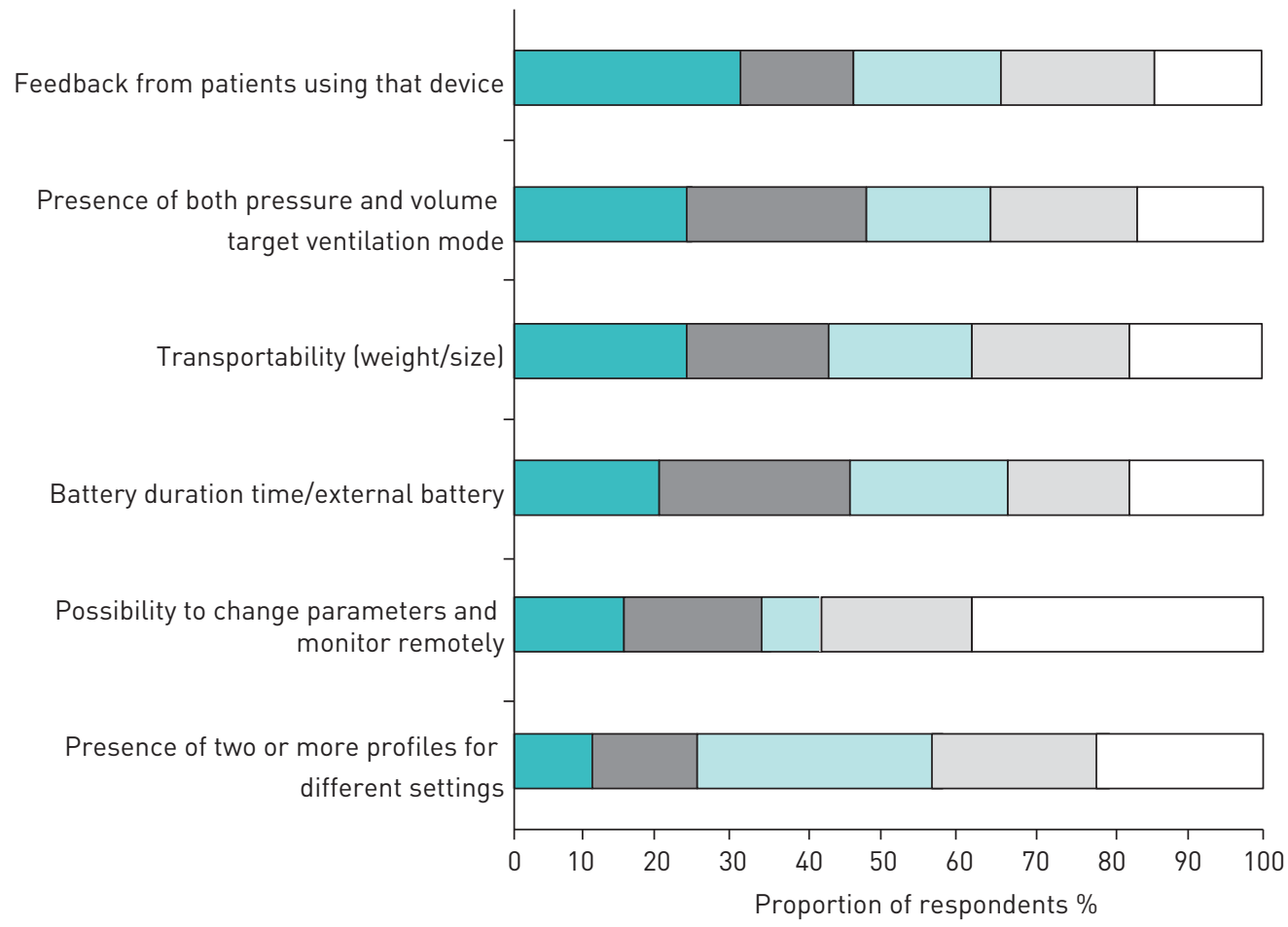

$\square$ Extremely important $\quad \square$ Very important $\quad \square$ Important $\quad \square$ Slightly important $\quad \square$ Least important 


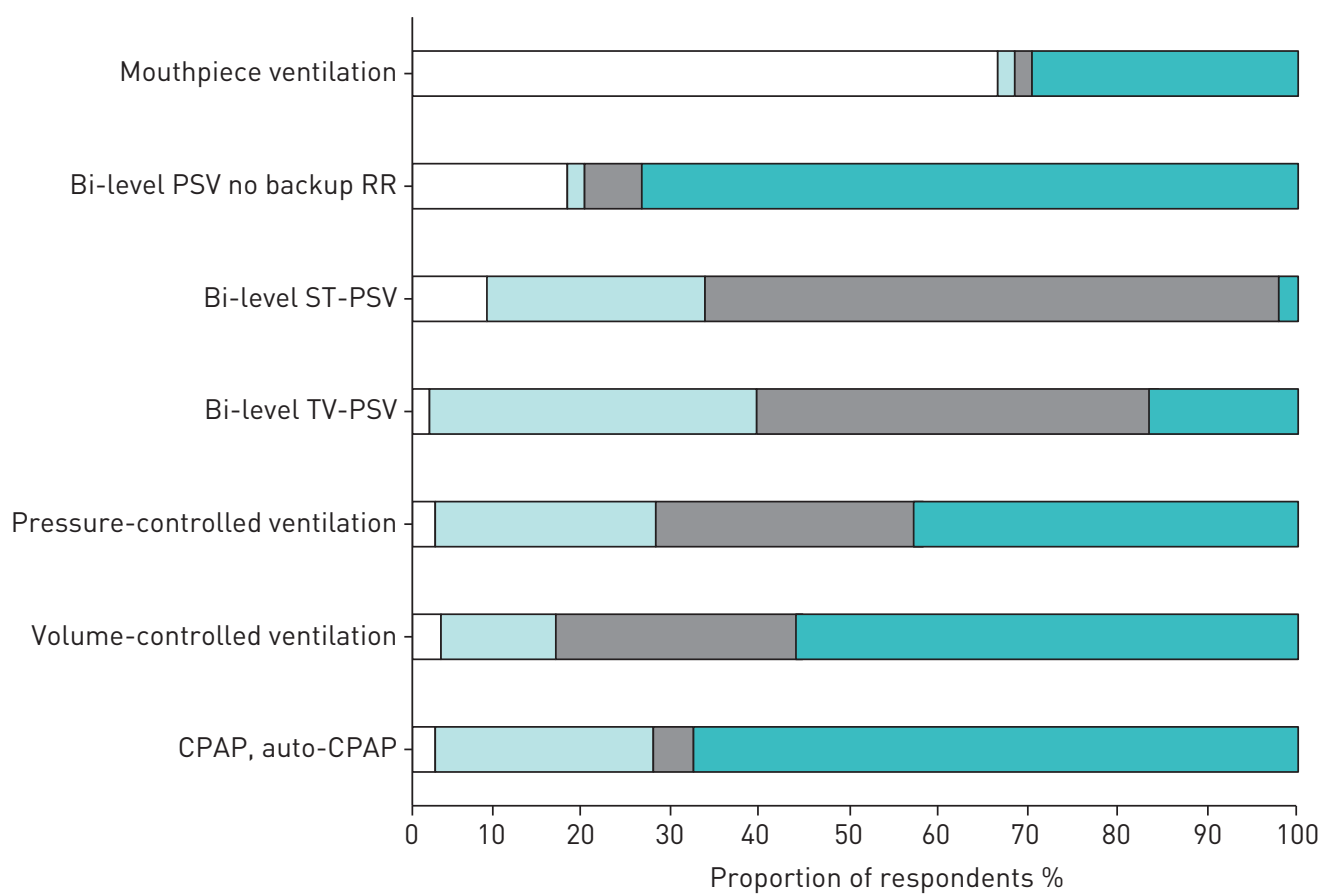

$\square$ Day $\square$ Night $\square$ Both day and night $\square$ I don't use it

FIGURE 4 Modes of ventilation. PSV: pressure support ventilation; RR: respiratory rate; ST: spontaneous-timed; TV: target volume; CPAP: continuous positive air pressure.

Interfaces preferred by all responders during day- and night-time ventilation are shown in figure 5 .

No further significant results were found from other comparisons among groups considered. Clinicians working both in general respiratory wards and critical care wards reported similar preferences in terms of modes of ventilation, interfaces and circuit configuration.

Most prescribers added humidification to NIV. A heated humidifier was the first choice (72\%) followed by heat and moisture exchangers (20\%). No humidification was prescribed in only $8 \%$ of cases.

\section{Patient follow-up}

The vast majority of responders initiated patients to NIV as inpatients (67\%). During the hospital stay, an educational programme was provided for new patients via either educational material combined with practical sessions for patient and caregiver (40\%) or only practical sessions for patient and caregiver (33\%). Lack of educational programmes was reported by $27 \%$ of respondents. The prescriber was usually also involved in long-term patient follow-up (95\%). Follow-up was performed during outpatient visits in $65 \%$ of cases, as inpatients in $18 \%$ and at home in $12 \%$. The remaining $5 \%$ of responders described a combined schedule of outpatient visit and telemedicine or ventilator telemonitoring. The different types of follow-up provided are reported in figure 6. Finally, in addition to follow-up visits described, in $65 \%$ of cases, a home care programme with control visits was provided through either a physician (11\%), a nurse (14\%), a physiotherapist $(11 \%)$ or a home care provider $(19 \%)$. The remaining responders $(10 \%)$ provided a home care programme combining at-home follow-up visit by healthcare practitioners (i.e. physician, nurse, physiotherapist) and telemedicine or telemonitoring. Conversely, in $35 \%$ of cases, the option of a home care programme was not available for RTD patients on LTHNIV.

\section{Discussion}

The REINVENT survey study explored clinicians' perspectives as to use of LTHNIV for RTD among professionals of different countries and members of the ERS assembly group on noninvasive respiratory support. 15 years after EUROVENT, this study describes the type of RTD patients requiring NIV, and the settings, modes and interfaces used. Survey response rate was $22.2 \%$, which is in line with reported response rates of internet-based surveys [23]. Responders were mainly physicians (80\%) involved in the care of NMD patients, primarily in teaching hospitals (64.8\%) and community hospitals (22.4\%). This corresponds with what was previously reported in EUROVENT [9]. The vast majority of responders (61\%) 


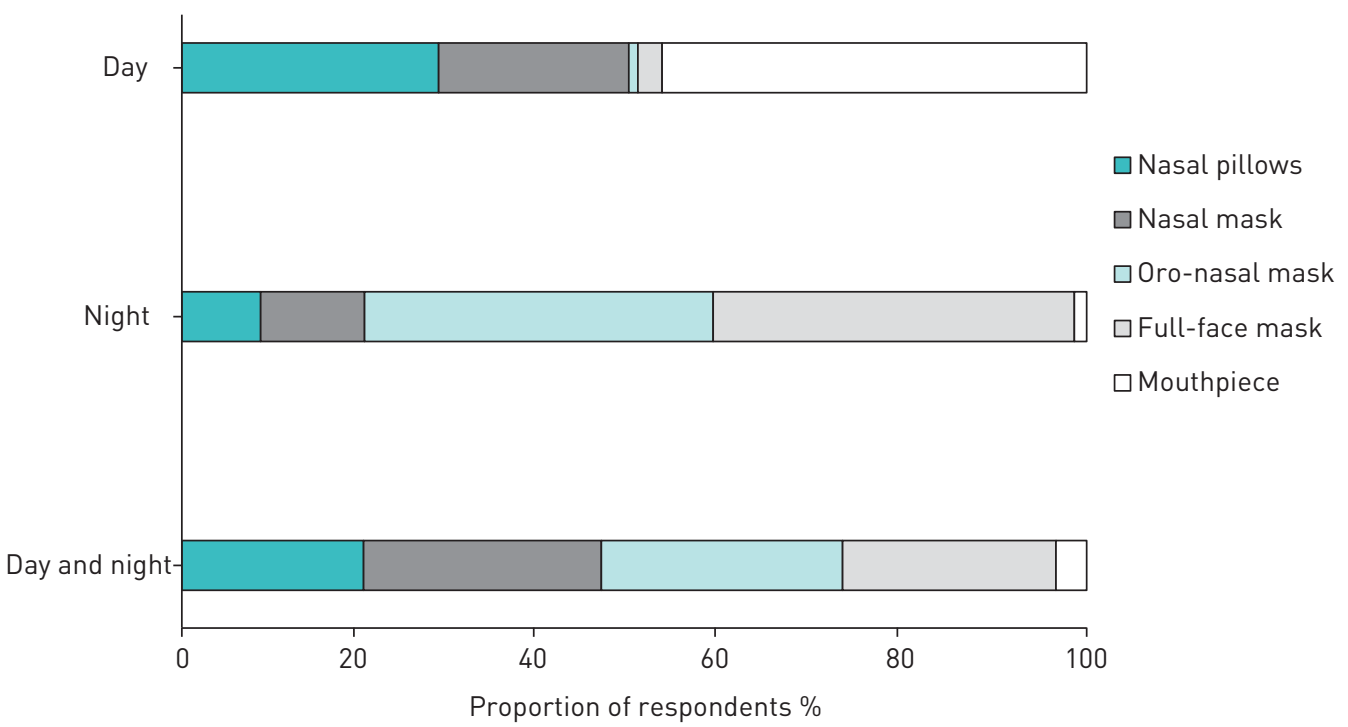

FIGURE 5 Interfaces used during long-term home noninvasive ventilation.

had extensive experience in LTHNIV (>10 years). Therefore, this study provides an indicative picture of experienced physicians working in the field of RTD.

The most important reasons for LTHNIV initiation were diurnal hypercapnia, hospitalisations for respiratory failure, muscle weakness symptoms and nocturnal hypercapnia. Interestingly, having a forced vital capacity $<80 \%$ predicted, which is recommended for NIV initiation in current ALS treatment guidelines, was not in the top three answers [24]. Targets of LTHNIV treatment were more often related to quality of life and quality of sleep than to increasing survival. It is likely that a lesser importance is given to survival in RTD patients and, in particular, in ALS patients, given their prognosis, which seems to be only partially influenced by LTHNIV [25-27]. More importance is given to the quality of patient's experience during LTHNIV used during day- and night-time [28]. Indeed, less evidence is present in the

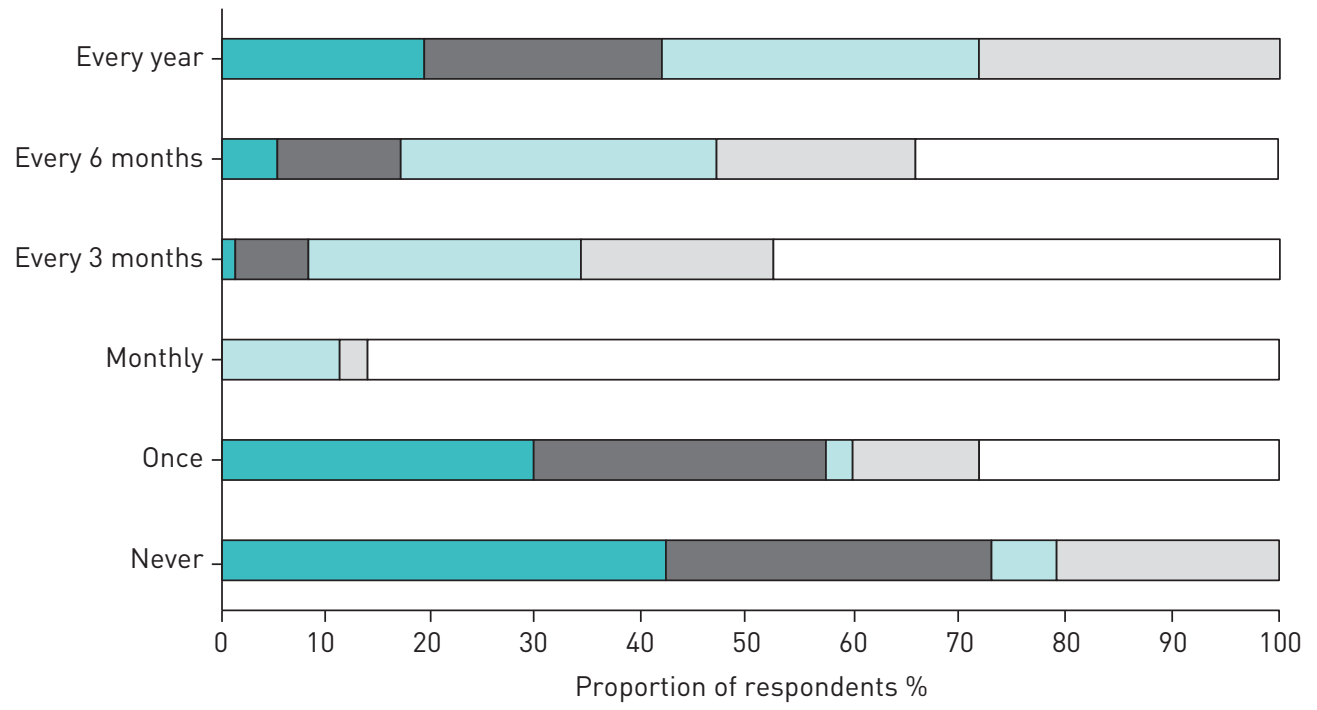

$\square$ Full sleep study (polysomnographyl $\square$ Portable home sleep study $\square$ Pulse oximetry $\square P_{\mathrm{tcCO}_{2}} \quad \square$ Nothing

FIGURE 6 Follow-up provided for long-term home noninvasive ventilation. $P_{\mathrm{tcCO}_{2}}$ : transcutaneous carbon dioxide tension. 
literature for LTHNIV in RTD use compared to other respiratory diseases such as COPD, where LTHNIV management has only recently been defined [29].

Interestingly, prescribers took into high consideration feedback from other patients already using the same machines. Indeed, such feedback was used in $25 \%$ of cases to drive the choice of the ventilator. Secondly, the presence of both pressure and volume modes was important: many prescribers chose hybrid modes with pressure and volume settings in RTD patients. Thirdly, transportability and battery autonomy or presence of an external battery were at the top of the list of aspects to consider when choosing a ventilator. Given the weakness and total dependence of NMD patients, these items play a vital role in patient autonomy. Patients may feel safe despite depending on the ventilator, and they may continue to enjoy a good quality of life moving around with their caregivers and outside their homes.

Ventilation modes with combined pressure and volume settings (hybrid modes: TV-PSV) are often chosen by the prescribers to be preferably used overnight. These results are interesting and deserve to be reviewed in depth. Indeed, hybrid modes are relatively new setting modalities in the LTHNIV scenario, and therefore their potential is yet to be explored [30]. These modes combine pressure and volume modes by delivering a targeted volume via a pre-defined pressure range (minimal and maximal inspiratory positive airway pressure) set on the ventilator [31]. There is no support in the literature for the use of these modes in long-term NIV. So why opt for them when the simple bi-level ST-PSV modality is widely used by prescribers and accepted by the patients? To date, only a few studies have explored the use of these hybrid modes in patients with obesity hypoventilation syndrome and chronic respiratory failure [32-34]. Although, intuitively in patients with RTD, hybrid modes could present several advantages, there is no evidence as yet in the literature as to their real effectiveness. For instance, their response in the presence of leaks may be unpredictable in NMD patients. Since many ventilators already provide these modes, and prescribers use them for the treatment of RTD patients as confirmed in this survey, studies are warranted to explore their benefit (or absence thereof) in more detail in this population. However, it is important to highlight that despite the larger use of hybrid modes, ST-PSV was the preferred mode for both daytime and night-time ventilation. This confirms the large knowledge and practicability of this mode among prescribers surveyed.

The extensive use of CPAP/auto-CPAP at night in RTD patients highlighted by this survey deserves comment. These modalities are not a ventilation mode, and they are not indicated in RTD, albeit in the presence of sleep-related disordered breathing (SDB). SDB may be one of the presenting symptoms in NMD patients. When using CPAP/auto-CPAP in NMD, a close follow-up is warranted to switch to bi-level support when required, and provide adequate respiratory support.

The most frequently used circuit is a single-limb tubing with an intentional leak port. This is in line with recent evidence describing this option as easier to use, and allowing a sufficient carbon dioxide exhalation compared to single or double limb circuits with expiratory valves [35].

According to this survey, in NMD (mostly ALS), mouthpiece ventilation is the most frequently used mode of daytime ventilation. Although nasal masks and nasal pillows are used less than mouthpieces during daytime ventilation only, when patients require prolonged ventilation during the day and at night-time, they become the first choice. Oro-nasal interfaces are used preferably for nocturnal ventilation only, probably to avoid excessive mouth leaks [18].

Humidification seems to be very important for prescribers who prefer active humidification ( $72 \%$ of cases) to heat and moisture exchangers (20\% of cases). Indeed, bronchial secretions may become very thick during prolonged ventilation; therefore, heated humidification plays a role in improving the rheology of secretions and overall quality of ventilation [36].

Follow-up was mainly provided by physicians via outpatient visits or via a home care provider. At the time of the survey a very large number of prescribers did not provide any home care programme. The picture has changed over recent months [37]. Indeed, a few randomised controlled trials have recently highlighted that initiation of mechanical ventilation at home is cost effective, improves health-related quality of life and is not inferior to hospital initiation for patients with RTD [38-42]. This survey was launched and concluded right before the coronavirus disease 2019 (COVID-19) pandemic, which had a profound impact on our way of managing LTHNIV patients. Social distancing has promoted the use of telemonitoring, telecommunication and televisiting within many specialties and for many patients. The scenario ahead of us will probably be very different: it may be preferable for these vulnerable patients to be managed by remote monitoring. A further upgrade to improve control and to modify ventilator settings remotely will probably be provided.

This study has a few limitations. Firstly, although the survey was conducted among members of the ERS assembly for NIV, specifically dedicated to noninvasive respiratory support, results may not be 
representative of physicians' clinical experience and perceptions of long-term NIV treatment of patients with RTD across Europe. Secondly, the $22 \%$ response rate could be considered as relatively low. However, it is in line with reported response rates for electronic surveys. In addition, some RTDs are rare diseases, sometimes managed only in few dedicated and specialised centres: this could have further affected the overall response rate. Thirdly, there may be a selection bias in this survey, with almost two-thirds of responders working in university teaching hospitals: this may impact on severity of cases, and choice of devices and settings.

The major strengths of our study are that it was the first study since EUROVENT that focused on LTHNIV in RTD. Secondly, respondents could not skip sessions or answers: therefore full data collection of respondents' opinions was guaranteed. Lastly, we gathered quality responses from healthcare professionals who are experts in this field.

In conclusion, the present REINVENT survey has provided a global picture of LTHNIV in patients with RTD and, in particular, with rare NMD who require long-term ventilation. Compared to the previous EUROVENT survey, it showed different reasons to initiate LTHNIV and goals to be achieved. Patterns of ventilation and modes used have changed considerably, highlighting the increase in use of combined modes in LTHNIV. Follow-up of these patients before the COVID-19 pandemic was mainly via outpatient visits or home care programmes with an in-person appointment. We expect that after the COVID-19 global pandemic, common practice will change significantly via the use of telemonitoring and telehealth techniques. Further studies are needed to evaluate what has changed in the clinical practice of LTHNIV in these patients affected by rare NMD.

Acknowledgements: P. Pierucci would like to thank S. Nava (Sant' Orsola-Malpighi Hospital, Bologna University, Bologna, Italy) for his great contribution in starting the project and helping to join all authors' forces together.

Author contributions: P. Pierucci, C. Crimi, A. Carlucci and R. Scala made substantial contribution to the conception and design of the work, and G.E. Carpagnano to the acquisition, P. Pierucci, C. Crimi and A. Noto to the analysis, and J-P. Janssens, M. Lujan, P.J. Wijkstra and W. Windisch to interpretation of data for the work. P. Pierucci, C. Crimi, A. Carlucci, G.E. Carpagnano, A. Noto and R. Scala contributed to drafting the article, and J-P. Janssens, M. Lujan, P.J. Wijkstra and W. Windisch to revising it critically for important intellectual content. All authors gave final approval of the version to be published, and agreed to be accountable for all aspects of the work and ensuring that questions related to the accuracy or integrity of any part of the work are appropriately investigated and resolved.

Conflict of interest: P. Pierucci has nothing to disclose. C. Crimi has nothing to disclose. A. Carlucci has nothing to disclose. G.E. Carpagnano has nothing to disclose. J-P. Janssens has nothing to disclose. M. Lujan has nothing to disclose. A. Noto has nothing to disclose. P.J. Wijkstra reports grants and personal fees from Philips and RESMED, grants from Goedegebuure and Vital Air, and personal fees from Bresotec and Synapse, outside the submitted work. W. Windisch reports grants from Weinmann Germany, Vivisol Germany, Heinen und Löwenstein Germany, VitalAire Germany and Philips/Respironics USA, during the conduct of the study; and personal fees from companies dealing with mechanical ventilation outside the submitted work. R. Scala has nothing to disclose.

\section{References}

1 Leger P, Bedicam JM, Cornette A, et al. Nasal intermittent positive pressure ventilation. Long-term follow-up in patients with severe chronic respiratory insufficiency. Chest 1994; 105: 100-105.

2 Köhnlein T, Windisch W, Köhler D, et al. Non-invasive positive pressure ventilation for the treatment of severe stable chronic obstructive pulmonary disease: a prospective, multicentre, randomised, controlled clinical trial. Lancet Respir Med 2014; 2: 698-705.

3 Chailleux E, Fauroux B, Binet F, et al. Predictors of survival in patients receiving domiciliary oxygen therapy or mechanical ventilation. A 10-year analysis of ANTADIR Observatory. Chest 1996; 109: 741-749.

4 Hind M, Polkey MI, Simonds AK. AJRCCM: 100-year anniversary. Homeward bound: a centenary of home mechanical ventilation. Am J Respir Crit Care Med 2017; 195: 1140-1149.

5 Sunwoo BY, Mulholland M, Rosen IM, et al. The changing landscape of adult home noninvasive ventilation technology, use, and reimbursement in the United States. Chest 2014; 145: 1134-1140.

6 Janssens JP, Derivaz S, Breitenstein E, et al. Changing patterns in long-term noninvasive ventilation: a 7-year prospective study in the Geneva Lake area. Chest 2003; 123: 67-79.

7 Cantero C, Adler D, Pasquina P, et al. Long-term noninvasive ventilation in the Geneva Lake area: indications, prevalence, and modalities. Chest 2020; 158: 279-291.

8 Radunovic A, Annane D, Rafiq MK, et al. Mechanical ventilation for amyotrophic lateral sclerosis/motor neuron disease. Cochrane Database Syst Rev 2017; 10: CD004427.

9 Lloyd-Owen SI, Donaldson GC, Ambrosino N, et al. Patterns of home mechanical ventilation use in Europe: results from the Eurovent survey. Eur Respir J 2005; 25: 1025-1031.

10 Bédard ME, McKim DA. Daytime mouthpiece for continuous noninvasive ventilation in individuals with amyotrophic lateral sclerosis. Respir Care 2016; 61: 1341-1348.

11 Pinto T, Chatwin M, Banfi P, et al. Mouthpiece ventilation and complementary techniques in patients with neuromuscular disease: a brief clinical review and update. Chron Respir Dis 2017; 14: 187-193.

12 Garuti G, Nicolini A, Grecchi B, et al. Open circuit mouthpiece ventilation: concise clinical review. Rev Port Pneumol 2014; 20: 211-218.

13 Carlucci A, Mattei A, Rossi V, et al. Ventilator settings to avoid nuisance alarms during mouthpiece ventilation. Respir Care 2016; 61: 462-467. 
14 Carlucci A, Gregoretti C. Mouthpiece ventilation: just a home-care support? Respir Care 2014; 59: 1951-1953.

15 Banfi P, Pierucci P, Volpato E, et al. Daytime noninvasive ventilatory support for patients with ventilatory pump failure: a narrative review. Multidiscip Respir Med 2019; 14: 38.

16 Crimi C, Pierucci P, Carlucci A, et al. Long-term ventilation in neuromuscular patients: review of concerns, beliefs, and ethical dilemmas. Respiration 2019; 97: 185-196.

17 Bach JR. Noninvasive respiratory management of patients with neuromuscular disease. Ann Rehabil Med 2017; 41: 519-538.

18 Hess DR. Noninvasive ventilation in neuromuscular disease: equipment and application. Respir Care 2006; 51: 896-911.

19 Benditt JO. Respiratory care of patients with neuromuscular disease. Respir Care 2019; 64: 679-688.

20 Crimi C, Noto A, Princi P, et al. A European survey of noninvasive ventilation practices. Eur Respir J 2010; 36: 362-369.

21 Crimi C, Noto A, Princi P, et al. Survey of non-invasive ventilation practices: a snapshot of Italian practice. Minerva Anestesiol 2011; 77: 971-978.

22 Crimi C, Noto A, Princi P, et al. Domiciliary non-invasive ventilation in COPD: an international survey of indications and practices. COPD 2016; 13: 483-490.

23 Cook DA, Wittich CM, Daniels WL, et al. Incentive and reminder strategies to improve response rate for internet-based physician surveys: a randomized experiment. J Med Internet Res 2016; 18: e244.

24 Andersen PM, Abrahams S, Borasio GD, et al. EFNS guidelines on the clinical management of amyotrophic lateral sclerosis (MALS) - revised report of an EFNS task force. Eur J Neurol 2012; 19: 360-375.

25 Hazenberg A, Kerstjens HA, Prins SC, et al. Is chronic ventilatory support really effective in patients with amyotrophic lateral sclerosis? J Neurol 2016; 263: 2456-2461.

26 Bourke SC, Tomlinson M, Williams TL, et al. Effects of non-invasive ventilation on survival and quality of life in patients with amyotrophic lateral sclerosis: a randomised controlled trial. Lancet Neurol 2006; 5: 140-147.

27 Pierucci P, Ambrosino N, Dimitri M, et al. The importance of maintaining the same order of performance of lung function and SNIP tests in patients with amyotrophic lateral sclerosis. Amyotroph Lateral Scler Frontotemporal Degener 2020; 21: 337-343.

28 Vrijsen B, Buyse B, Belge C, et al. Noninvasive ventilation improves sleep in amyotrophic lateral sclerosis: a prospective polysomnographic study. J Clin Sleep Med 2015; 11: 559-566.

29 Ergan B, Oczkowski S, Rochwerg B, et al. European Respiratory Society guidelines on long-term home non-invasive ventilation for management of COPD. Eur Respir J 2019; 54: 1901003.

30 Arellano-Maric MP, Gregoretti C, Duiverman M, et al. Long-term volume-targeted pressure-controlled ventilation: sense or nonsense? Eur Respir J 2017; 49: 1602193.

31 Windisch W, Storre JH. Target volume settings for home mechanical ventilation: great progress or just a gadget? Thorax 2012; 67: 663-665.

32 Murphy PB, Davidson C, Hind MD, et al. Volume targeted versus pressure support non-invasive ventilation in patients with super obesity and chronic respiratory failure: a randomised controlled trial. Thorax 2012; 67: 727-734.

33 Storre JH, Seuthe B, Fiechter R, et al. Average volume-assured pressure support in obesity hypoventilation: a randomized crossover trial. Chest 2006; 130: 815-821.

34 Janssens JP, Metzger M, Sforza E. Impact of volume targeting on efficacy of bi-level non-invasive ventilation and sleep in obesity-hypoventilation. Respir Med 2009; 103: 165-172.

35 De Mattia E, Falcier E, Lizio A, et al. Passive versus active circuit during invasive mechanical ventilation in subjects with amyotrophic lateral sclerosis. Respir Care 2018; 63: 1132-1138.

36 Esquinas Rodriguez AM, Scala R, Soroksky A, et al. Clinical review: humidifiers during non-invasive ventilation key topics and practical implications. Crit Care 2012; 16: 203.

37 Schwarz SB, Windisch W. Outpatient noninvasive ventilation: can the Dutch setting serve as a blueprint for other countries? Chest 2020; 158: 2255-2257.

38 van den Biggelaar RJM, Hazenberg A, Cobben NAM, et al. A randomized trial of initiation of chronic noninvasive mechanical ventilation at home $v s$ in-hospital in patients with neuromuscular disease and thoracic cage disorder: the Dutch Homerun trial. Chest 2020; 158: 2493-2501.

39 Hazenberg A, Kerstjens HA, Prins SC, et al. Initiation of home mechanical ventilation at home: a randomised controlled trial of efficacy, feasibility and costs. Respir Med 2014; 108: 1387-1395.

40 Bertella E, Banfi P, Paneroni M, et al. Early initiation of night-time NIV in an outpatient setting: a randomized non-inferiority study in ALS patients. Eur J Phys Rehabil Med 2017; 53: 892-899.

41 Sheers N, Berlowitz DJ, Rautela L, et al. Improved survival with an ambulatory model of non-invasive ventilation implementation in motor neuron disease. Amyotroph Lateral Scler Frontotemporal Degener 2014; 15: $180-184$.

42 Duiverman ML, Vonk JM, Bladder G, et al. Home initiation of chronic non-invasive ventilation in COPD patients with chronic hypercapnic respiratory failure: a randomised controlled trial. Thorax 2020; 75: $244-252$. 